radio-elements could contribute an appreciable quantity of heat only before $1.5 \times 10^{9}$ years ago.

The new method should facilitate adequate rapid observation (geothermal problems) of great numbers of rock specimens, and should thus in due course present us with a mass of observational data for the study of the influence of heat derived from radioactive materials on the thermal history of the earth, besides contributing data to assist in the solution of present geotectonic problems.

\section{BEHAVIOUR OF SULPHUR IN RUBBER}

A

CCORDING to G. G. Winspear (Bell Lab. Rec., 20, No. 8, April, 1942) vulcanized rubber may have a wide variety of characteristics depending on the amount of sulphur, the period and temperature of vulcanization, and the other substances compounded with it. Identical rubber compositions, vulcanized for the same time and at the same temperature, do not always develop the same characteristics. One of the unsatisfactory conditions that sometimes appears is spottiness, indicating a lack of homogeneity in the product. Before the sulphur assumes a position in the rubber molecule, it dissolves, and to secure uniform solution the sulphur is first dispersed evenly throughout the rubber mass. When sulphur and rubber are mixed on a mill the sulphur is dispersed throughout the rubber mass but most of it is in particles of measurable size. Although the particles may be small, and perhaps even invisible to the unaided eye, they are still very large compared to the sulphur molecule, so that the mixture is far from being one where all the sulphur is in immediate contact with the rubber molecules, which is the theoretical state required to give a homogeneous solution of sulphur in rubber. Such an intimate mixture results from a diffusion of the sulphur of each particle following the dispersion on the mill.

If rubber including a small percentage of sulphur is thoroughly mixed and then held for a long enough time at a high enough temperature, all the sulphur will go into solution. From its original particles the sulphur will diffuse until the whole mass of rubber is thoroughly permeated, and if the temperature is high enough all the sulphur will be dissolved. Rubber in thin sheets with completely dissolved sulphur is clear ard transparent while if it contains undissolved sulphur crystals it will be cloudy. After a known amount of sulphur has all been dissolved in a sheet of rubber some of the sulphur will begin to crystallize out if the temperature is lowered sufficiently, because the lower the temperature the less sulphur will the rubber dissolve. This precipitation of sulphur will be evidenced by the fact that rubber will take on a cloudy appearance.

The interval between mixing and vulcanization is also important. At the end of the mixing period the rubber is at a fairly high temperature and the amount of sulphur in solution will correspond to this temperature. If the rubber is now set aside it will cool and some of the sulphur will crystallize in fine struc. ture dendritic form. When the rubber is again heated in the vulcanizing process the crystals go back readily into solution. If the rubber is allowed to stand for a more extended period before vulcanization, however, the dendritic crystals gradually change to larger rhombic sulphur crystals, so that when the rubber is vulcanized, the sulphur thus crystallized cannot as readily get back into solution because of the time required for completely dissolving these larger crystals. The formation of these rhombic crystals is undoubtedly the cause of some of the spotty conditions sometimes found in vulcanized rubber.

\section{ELECTRICAL ENGINEERING IN THE UNITED STATES}

ARCHER E. KNOWLTON, associate editor of the Electrical World (United States), in a review (J. Inst. Elec. Eng., 89, Pt. 1, No. 18, June, 1942) of electrical engineering progress in the United States during the past 2-21 years, points out that in 1941 and after, investigation and research have been redirected substantially towards military measures. Many developments arising out of the pressure for superior arms of every description are already regarded as having great import for the resumption of peace-time pursuits. Weights of electrical equipment are likely to be reduced as the results of iron research, and working temperatures of many kinds of equipment may be increased on account of alloy research.

Outstanding in the latter half of the period under review were the incentives to standardize, to simplify, to eke out and to compensate, in order that suddenly taxed systems could meet the exacting requirements of defence loadings with the least drain on capital, production facilities and installation forces. Also, the technique of proofing overhead lines against lightning made it possible to render a single line practically as reliable in performance as double circuits had been. Higher speed circuit-breakers, reclosure, earth-fault neutralizers, protector tubes, counterpoises, arresters, insulation co-ordination for impulses were all factors in creating effective immunity to the surges which precipitate outages.

In the field of power distribution, reliability of service vied with the imperative need for conservation of capital, and these two somewhat contradictory objectives can claim the bulk of the developments in power distribution. Among these might be mentioned sectionalization of radial feeders, reclosure, networks, banking of secondaries, rebalanced transformer losses, extensive application of corrective capacitors, surveys of thermal margins of apparatus, unit substations, step regulators, improved cables, etc. Change and uncertainty of location of defence loads, as well as the provision of spares for emergencies, have more recently prompted a considerable adoption of portable substations and capacitor banks.

The paper reviews more particularly and in a very condensed form the developments which have taken place in large generators, power generation, transformers, transmission, circuit interruption, relaying, lightning, switching and substations, cables, insulation, capacitors, power distribution, instruments, electronics and electrostatics, motors and control, industrial applications, transportations, rectifiers, electrothermics and electrochemistry, welding, illumination, and certain miscellaneous developments. 